\section{A ABORDAGEM DA EDUCAÇÃO AM- BIENTAL NA SALA DE AULA DA EMEF SERGIO FRANCISCO DA SILVA}

\author{
THE APPROACH OF ENVIRONMENTAL \\ EDUCATION IN THE CLASSROOM OF \\ EMEF SERGIO FRANCISCO DA SILVA
}

Davi Prado Lima

Ann Letícia Aragão Guarany

\begin{abstract}
Resumo
Diante das transformações cada vez mais aceleradas que acontecem pelo mundo, a Educação Ambiental (EA) passou a ser essencial nas discussões do cotidiano social, pois há um constante desafio em construir uma sociedade sustentável. Neste contexto, a escola tem papel fundamental, mas poucas são as que se preocupam em trabalhar esse tema como algo contínuo e problematizador. Por isso, através de pesquisas bibliográficas e aplicações de questionários em uma escola municipal de Aracaju-SE, decidiu-se verificar como se dá a abordagem da EA a partir da análise do Projeto Político Pedagógico (PPP) da escola, bem como se os professores desta unidade de ensino abordam a EA com os discentes e qual o conceito destes em relação ao tema. Através deste trabalho observou-se que o PPP da escola não contempla de forma clara a EA, bem como há uma abordagem branda por parte dos professores. Já os alunos demostram conhecimento superficial da EA.
\end{abstract}

Palavras-chave: Educação Ambiental, sustentabilidade, escola.

\begin{abstract}
In the face of the increasingly accelerating transformations taking place around the world, Environmental Education (EE) has become essential in the discussions of social everyday life, as there is a constant challenge in building a sustainable society. In this context, the school has a fundamental role, but few are concerned with working on this theme as something continuous and problematizing. Therefore, through bibliographic research and questionnaire applications at a municipal school in Aracaju-SE, it was decided to verify how the EE approach is approached from the analysis of the School's Political Pedagogical Project (PPP), as well as whether teachers of this unit of education approach EE with the students and what the concept of these in relation to the theme. Through this work it was observed that the PPP of the school does not clearly contemplate the EE, as well as there is a soft approach on the part of the teachers. Already students demonstrate superficial knowledge of EE.
\end{abstract}

Keywords: Environmental Education, sustainability, school. 


\section{Introdução}

A modernidade e a tecnologia estão progredindo rapidamente para nosso bem-estar e conforto. Infelizmente há um custo cada vez mais alto das consequências que nos faz pensar em alternativas mais sustentáveis e uma forma diferente de se relacionar com o restante do meio. Mas esse pensamento não é comum a todos, principalmente quando se fala de grandes empresas entre as quais a concorrência é acirrada e o lucro vem basicamente do consumo. Então, cabe à escola educar os alunos (futuros consumidores) para a importância do consumo consciente, de refletir sobre suas ações em sociedade e com seu ambiente para a sustentabilidade do planeta.

Como professor licenciado em Ciências Biológicas, reflito e penso em nossa imensa responsabilidade para com o futuro da nossa comunidade, do nosso país, visto que ensinamos ao futuro do planeta, nossas crianças. Se a Educação Ambiental (EA) não é abordada na sala de aula como realmente deve ser, como poderemos esperar no futuro um meio saudável para se viver? A EA é um tema transversal e interdisciplinar, ou seja, esse tema gerador deve ser abordado por todos os professores em suas respectivas matérias durante todo o calendário letivo. Entretanto, justamente por ser um tema transversal e não ter conteúdo específicos, muitos professores não o abordam e quando o fazem, é de maneira superficial ou pontual como as comemorações de datas específicas.

$\mathrm{Na}$ Escola Municipal de Ensino Fundamental (EMEF) Sérgio Francisco da Silva, onde estou lotado, não é diferente. Observo que não existe uma preocupação por parte dos alunos em relação a esse tema. Muitos não possuem consciência ambiental com o ambiente da escola e ao seu redor, pois muitos alunos deixam a desejar em relação à higiene, ao cuidado com a escola, com a higiene, patrimônio, comunidade, resíduos entre outras situações. Penso, então, que a EA trabalhada de forma contextualizada e crítica ajudará os discentes a ter um melhor relacionamento consigo mesmos e com o ambiente que eles frequentam, seja na escola, em casa, na comunidade ou em qualquer outro lugar.

Portanto, esse artigo visa a analisar como se dá a abordagem da EA nesta unidade de ensino. Para isso averiguou-se como esse tema consta no Projeto político pedagógico (PPP) da escola, bem como entender em que medida os docentes inserem a EA na sala de aula, além de identificar qual o conceito de EA que os discentes da EMEF Sérgio Francisco da Silva possuem. Esse artigo foi produzido durante o curso de Educação Ambiental com ênfase em espaços educadores sustentáveis da Universidade Federal de Sergipe (UFS).

\section{Histórico e consequencias ambientais}

A história da humanidade sempre foi marcada pela relação íntima com a natureza, dada a dependência do seu meio. Os primeiros seres humanos do planeta enfrentaram enormes dificuldades e desafios, pois a natureza os afetava mais do que era afetada por eles. Naquela época o conhecimento ambiental que passava de geração para geração também era necessário, tanto para a proteção contra os ataques da natureza, quanto para melhor aproveitamento de suas riquezas. Isso mudou com a evolução da civilização (EFFTING, 2007).

A autora discute ainda que a natureza antes temida e poderosa passou a ocupar para o homem um patamar de subserviência, e cresceu a busca do homem pelo retirar, consumir e descartar. A partir da revolução industrial, a natureza passou a ser administrada como fonte de recursos infinitos, gerando o esgotamento dos recursos naturais, a destruição de ecossistemas e a perda da biodiversidade. Nos dias atuais tudo se tornou prático e descartável. A grande maioria das pessoas não consegue perceber a estreita relação que tem com o meio ambiente e nem dimensiona as consequências que pequenos atos exercem sobre a natureza e o que ela nos oferece.

Enquanto isso, convivemos num sistema cada vez mais capitalista em que as cidades estão crescendo de forma contínua e com elas o consumismo desenfreado. Com maior quantidade de asfalto e concreto, mais raios ultravioletas são refletidos à atmosfera que a reflete de volta à superfície e assim sucessivamente, ocasionando um efeito estufa exacerbado e o aumento da temperatura, derretimento das calotas polares, aumento do nível do mar alterando o funcionamento da vida em diversos pontos do planeta, podendo levar 
até mesmo à extinção de algumas espécies. A situação dos rios também não é muito saudável. Muitos perderam suas matas ciliares diminuindo sua vida útil e o esgoto é diversas vezes jogado em seus leitos sem nenhum tratamento. (JACOBI, 2003; CARMO, 2007).

Ainda segundo os autores, as nascentes estão desaparecendo por conta do desmatamento, e o percentual de água doce disponível para a população mundial está baixo. A qualidade do ar está cada vez pior num mundo em que está se desmatando muito e se plantando pouco. A valorização e busca por energia para alimentar o mundo em crescimento está em ritmo ascendente, e se busca sempre novos pontos de captação o que altera todo um ecossistema. O problema do lixo não fica para trás: com o aumento da população e com os produtos cada vez mais descartáveis, a produção de lixo também está crescendo, além do descarte irregular de materiais mais nocivos.

Diante disso, diversos movimentos em prol do meio ambiente vêm lutando para tentar sensibilizar a sociedade e diminuir a degradação ambiental ou pelo menos encontrar novas alternativas para processos de produção e consumo menos impactantes, pois o mundo atual é marcado pela degradação contínua do meio ambiente e de seus ecossistemas. Ao longo do tempo, trabalharam-se bem os termos "educação" e "saúde", e, só mais recentemente, o termo "meio ambiente" foi se incorporando à lista de temas importantes a se trabalhar nas escolas e na sociedade (PELEGRINI; VLACH, 2011).

\section{Eucação ambiental nas escolas}

Nos anos 70, a conferência de Estocolmo marcou o início da preocupação mundial com o futuro do planeta. Deram embasamento à Educação Ambiental as conferências da Eco-92 que trouxeram a discussão da EA para a prática em sala de aula em vários países (JACOBI, 2003; ESTEVAN, PESTANA e LEAL, 2008; FELIZOLA e COSTA, 2012).

Criou-se uma legislação específica com a lei n. 9.795/99, que define a Educação Ambiental como sendo aquela em que o indivíduo e a coletividade constroem valores sociais, habilidades e competências voltadas para a conservação do meio am- biente, fato essencial para a qualidade de vida e sua sustentabilidade. A lei também aborda que a Educação Ambiental deva estar articulada em todos os níveis e modalidades de ensino formal e não formal de maneira interdisciplinar (BRASIL, 1999).

Já nos artigos $7^{\circ}$ e $8^{\circ}$ da resolução n. 2 , de 15 de junho de 2012, está garantida a plena discussão da EA em todos os níveis de ensino sendo ela componente integrante e permanente da educação nacional, devendo ser desenvolvida de forma integrada e interdisciplinar. Já nos artigos $15^{\circ} \mathrm{e}$ $16^{\circ}$ da mesma resolução, observa-se a importância do PPP, dos projetos e dos planos de curso na organização curricular, sendo esta adequada à idade, etapas e diversidade cultural dos estudantes e de suas comunidades de vida, dos biomas e dos locais onde se situam as unidades de ensino. A inserção da EA nos currículos pode ocorrer pela transversalidade ou como conteúdo dos componentes já constantes no currículo (BRASIL, 2012).

Entretanto, apesar de garantida por lei e do comprometimento do MEC em afirmar a transversalidade da EA, ela ainda é pouco abordada nas escolas de ensino básico do país. Muitos professores desconhecem o termo transversalidade e quando abordam a EA com os discentes, o fazem de forma pontual e muitas vezes em datas comemorativas. Ou seja, a escola está trabalhando informações e conceitos, mas está se esquecendo de transmitir valores. Somente ela é capaz de formar cidadãos mais comprometidos com o futuro do planeta. Daí a importância da educação ambiental, pois irá proporcionar ao aluno realizar ações orientadas de práticas pedagógicas que implicaram mudanças em sua realidade local (GALLO, 2001; GADOTTI, 2006).

Portanto, é clara a importância da EA no sentido de provocar uma mudança de atitude principalmente entre os mais jovens, para que ajam de maneira mais racional e com responsabilidade, relacionando-se com o ambiente de maneira sustentável, exigindo seus direitos e os do próximo, tanto em seu bairro como por causas internacionais, para que se modifiquem como pessoas e nas suas relações com o meio ambiente. E a escola é um espaço privilegiado para estabelecer essas conexões, criando condições e alternativas que 
estimulam os alunos a terem concepções e posturas cidadãs, cientes de suas responsabilidades e principalmente perceberem-se como integrantes do meio ambiente (CUBA, 2010).

Sendo assim, é necessária sua abordagem constante, principalmente no nível básico de ensino para que a sociedade busque práticas e movimentos de ação e reflexão através dos educadores para a formação de uma consciência ambiental crítica. Pensando nesta problemática e sabendo da importância da abordagem ambiental no ensino básico, é que decidi averiguar como ocorre a mesma na EMEF Sérgio Francisco da Silva.

\section{Metodologia}

Para o desenvolvimento deste trabalho, utilizou-se como referencial: pesquisas na internet, revisão literária e bibliográfica além de pesquisa in loco, na EMEF Sérgio Francisco da Silva, no município de Aracaju-SE.

Primeiramente esta pesquisa partiu do estudo do PPP da unidade, a fim de se constatar se a EA era contemplada. Depois foi analisado se esse tema transversal era abordado de fato na sala de aula e de que forma. Para isso, foram aplicados questionários com essa temática aos professores do $6^{\circ}$ ao $9^{\circ}$ ano do ensino fundamental.

Responderam ao questionário quatorze professores de um total de quinze professores da escola. Destes, um professor de Português, três de Matemática, dois de História, três de Geografia, um de Educação Física, um de Inglês, dois de Ciências e um de Artes. Somente um professor não demostrou interesse em responder o questionário. Esse total representa todos os professores desse nível de ensino sendo dez efetivos e quatro de contratação temporária. Foram escolhidos professores de todas as áreas por entender que a EA não deve ser trabalhada somente pelos professores de Ciências. Sendo um tema transversal, é de responsabilidade de todo o corpo docente da escola.

O questionário dos professores consistia em perguntas, 7 objetivas e 3 subjetivas que davam a possibilidade de o professor descrever seu conceito de EA, bem como mostrar seu conhecimento sobre os documentos oficiais acerca desse tema e se costumava realizar atividades voltadas à temática ambiental com os alunos. Além das perguntas específicas, havia campos de preenchimento para que o professor indicasse alguns dados como tempo de docência, sexo, habilitação, turmas em que trabalha na escola e a atual situação funcional, se contratado ou efetivo.

Foi aplicado também questionários aos alunos do $6^{\circ}$ ao $9^{\circ}$ ano do ensino fundamental maior, com idade de 11 a 15 anos, a fim de verificar a perspectiva deles em relação à EA. Na EMEF Sérgio Francisco existem 9 turmas de ensino fundamental maior, totalizando cerca de 300 alunos. Foi retirada então uma amostra aleatória de 45 alunos, sendo 5 alunos por turma. Para a escolha destes, perguntou-se em cada turma quem desejava participar. Os cinco primeiros alunos de cada turma que se manifestaram favoráveis a responder foram escolhidos.

O questionário aplicado com os alunos continha 10 perguntas, 8 objetivas e 2 subjetivas que davam a possibilidade de o aluno descrever o que entendiam por EA bem como mostrar o que faz parte do meio ambiente para ele. Além das perguntas específicas, havia campos de preenchimento para que o aluno indicasse alguns dados como sexo, idade, o ano do ensino fundamental que está cursando e o turno em que estuda. Tanto o questionário dos professores quanto o dos alunos continham no final um espaço para comentários, caso achassem necessário complementar alguma resposta.

Após a aplicação dos questionários, foi feita a tabulação e interpretação dos dados. Essa pesquisa se apoia nas abordagens qualitativa e quantitativa e foi realizada no período de maio a julho de 2016 .

\section{Resultados e discussão}

A EMEF Sérgio Francisco da Silva localiza-se na av. Lamarão, sem número, bairro Lamarão, região norte de Aracaju, oferecendo à comunidade as seguintes modalidades de ensino: Ensino fundamental $\mathrm{I}$, com turmas do $1^{\circ}$ ao $5^{\circ}$ ano; Ensino fundamental II, com turmas do $6^{\circ}$ ao $9^{\circ}$ ano; Programa de aceleração de jovens e adultos (PAEJA), com turmas do $1^{\circ}$ e $2^{\circ}$ ciclo; e Educação de jovens e adultos (EJA), com turmas do $6^{\circ}$ 
ao $9^{\circ}$ ano. A instituição conta também com acompanhamento pedagógico diferenciado para crianças com dificuldades de aprendizagem. $\mathrm{O}$ último Índice de desenvolvimento da educação básica (IDEB), calculado em 2015 foi de 4.7 (BRASIL, 2015).

Analisando o PPP desta unidade de ensino, nota-se que o mesmo é bem elaborado e organizado. Estão presentes as características físicas, gerenciais e de recursos humanos da escola. Encontra-se também no projeto a caracterização pedagógica, bem como o rendimento escolar e a nota do IDEB, além dos objetivos, metas, a proposta pedagógica da escola e os projetos trabalhados. Apesar de o PPP abordar a EA em seus objetivos como: estimular a formação de hábitos higiênicos para conservar e preservar a saúde; favorecer o desenvolvimento socioambiental; estimular o respeito ao ser humano em sua diversidade étnico-racial, entre outros, não há uma especificidade de trabalho com esse tema em seus projetos pedagógicos, ficando ao cargo de datas comemorativas ou feiras de ciências a abordagem ambiental.

No PPP observado, há o programa "Mais educação", que visa ao ensino dos alunos no turno oposto ao matriculado, através de atividades que venham a reforçar o conteúdo estudado, bem como a prática de esportes e lazer, cultura, artes, promoção à saúde e também da educação ambiental (LECLERC e MOLL, 2012). No entanto na escola, só acontece o desenvolvimento de oficinas de acompanhamento pedagógico de esportes como karatê, capoeira e handebol; de música como aulas de violão e flauta barroca.

A EA no programa "Mais educação" é então contemplada no sentido de cuidar da formação do indivíduo, mas não há um foco no ambiente que rodeia o aluno nem mesmo mais global por meio de atividades específicas nem como um dos objetivos das oficinas a serem oferecidas. Infelizmente durante o ano de 2016, ainda não tinha sido iniciado o projeto devido à falta de verba para pagar aos oficineiros.

Para analisar se a educação ambiental é abordada de fato na sala de aula e como esta ocorre, foram aplicados questionários. Abaixo, encontram-se as tabelas e figuras com os resultados obtidos sobre a Educação Ambiental (EA) dos professores e alunos mediante pesquisa de campo.

No questionário dos professores, a primeira pergunta referia-se ao conhecimento dos mesmos em relação ao PPP da escola (Tabela 1).

Tabela 1- Os professores conhecem o Projeto Político Pedagógico da EMEF Sérgio Francisco da Silva?

\begin{tabular}{|l|c|}
\hline Sim & 4 \\
\hline Não & 10 \\
\hline
\end{tabular}

Fonte: Elaboração do autor, 2016.

Do total de professores abordados, dez dizem não conhecer o PPP escolar e somente quatro o conhecem. Isso se deve principalmente ao fato da grande rotatividade de professores que ocorreu no início do ano após o início das aulas.

Apesar de o PPP estar disponível para o corpo docente, os professores novatos quase nunca procuram obter e conhecer o documento que retrata a identidade da escola a fim de se apropriar dele e assim ter condições de melhorá-lo em tempo oportuno. Somente alguns dos professores mais antigos ou os que já participaram da semana pedagógica antes do ano letivo dizem conhecer o PPP escolar. Esta análise é possível quando observamos a resposta a essa pergunta, associando-a à informação do tempo de docência na escola e na rede municipal. Dos professores abordados, somente três possuem mais de 3 anos de magistério na EMEF Sérgio Francisco.

Sem a atitude dos professores na elaboração e cumprimento, o PPP não se torna político nem eficaz, sendo apenas mais um documento burocrático em gaveta. Ele não deve ser um documento acabado, mas sempre passar por atualizações e renovações através de constantes avaliações, pois, por meio da análise de onde estamos e aonde queremos chegar, pode-se perseguir os objetivos, a fim de se atender os anseios e demandas da comunidade escolar, que só podem ser diagnosticados de maneira eficiente com a participação de todos, principalmente quando se quer focar nos temas transversais como a EA (LONGHI; BENTO, 2006). Se não estiver claro no PPP da escola como serão trabalhados esses temas, o ensino poderá ficar "solto", sem norte, dando margem para 
o não-cumprimento dos objetivos. Infelizmente. Isso é o que se vê na maioria das escolas públicas, e a EMEF Sérgio Francisco não foge à regra.

Foi perguntado aos docentes se estes participaram da construção do PPP da escola que chegamos aos dados da Tabela 2.

Tabela 2 - Os docentes participaram da construção do PPP da scola?

\begin{tabular}{|c|l|}
\hline Sempre & 3 \\
\hline Frequentemente & 3 \\
\hline Algumas vezes & 2 \\
\hline Nunca & 0 \\
\hline Não sei & 6 \\
\hline
\end{tabular}

Fonte: Elaboração do autor, 2016.

Comparando as tabelas 1 e 2, percebemos que entre os professores que disseram já terem participado da construção do PPP da escola também estão os que afirmaram que conhecem o documento. Interessante observar que dois dos três professores que responderam que participaram frequentemente e os que responderam que somente algumas vezes participaram de sua elaboração afirmaram não conhecer o documento. Isso se deve ao fato da participação superficial dos mesmos na sua elaboração. Alguns professores dizem não saber por não estarem presentes na escola no momento da elaboração ou atualização do PPP, já que alguns são contratados e chegaram depois do início do ano letivo. Entretanto, sabe-se que o documento está disponível para consulta e leitura, mas poucos são os que o solicitam para tal. Isso acontece provavelmente devido à falta de familiarização deles para com este documento e do reconhecimento de que as atividades da escola partem do atendimento aos objetivos do PPP como deveria ocorrer.

Diante do reconhecimento da importância do trabalho com EA nas escolas e na formação do professor, foi questionado aos docentes se os mesmos constataram que na grade de sua formação acadêmica a educação ambiental tinha sido abordada (Tabela 3).

Tabela 3 - Na grade de sua formação acadêmica, foi abordado a EA?

\begin{tabular}{|c|c|}
\hline Sim & 7 \\
\hline Não & 7 \\
\hline Não sei & 0 \\
\hline
\end{tabular}

Fonte: Elaboração do autor, 2016.

Do total de professores questionados, metade relatou que sim. A Educação Ambiental tinha sido abordada na sua formação. Isso mostra que já é crescente o trabalho com EA nas universidades, mas ainda não é um consenso. Dos sete professores que afirmaram não terem visto a EA na universidade, quatro já lecionam há mais de 20 anos. Isso pode demonstrar que a formação docente há algumas décadas não tinha uma preocupação clara com a EA. A não ser que o foco da formação fosse nas disciplinas Ciências ou Geografia, os demais licenciandos não tinham a "obrigação" de estudar EA.

Isso com certeza é um fator que colabora para a dificuldade de aplicação desse tema com os alunos. O artigo 19 das Diretrizes Curriculares Nacionais para a Educação Ambiental estabelece que as instituições formadoras de profissionais da educação básica e superior devem promover o desenvolvimento didático-pedagógico da dimensão da EA na sua atuação escolar e acadêmica, com foco na metodologia integrada e interdisciplinar (CONSELHO NACIONAL DE EDUCAÇÃO, 2012). A efetividade do cumprimento das Diretrizes pode colaborar para a formação de novos professores que poderão colocar em prática com os alunos o que aprenderam.

Entretanto, apesar de nem todos os docentes terem visto a EA em sua formação, nota-se que a grande maioria percebe a importância de trabalhá-la com seus alunos (Tabela 4).

Tabela 4 - Você acha importante abordar a EA na sala de aula?

\begin{tabular}{|c|c|}
\hline Sim & 13 \\
\hline Não & 0 \\
\hline Às vezes & 1 \\
\hline
\end{tabular}

Fonte: Elaboração do autor, 2016.

Dos professores abordados, treze relataram achar importante. Apenas um professor informou que somente às vezes é importante abordar a EA em sala de aula, muito provavelmente devido ao extenso conteúdo curricular a cumprir. Muitas ve- 
zes o professor até tem a boa vontade de inserir um projeto na escola, mas, devido à escassez de tempo, acaba sempre deixando para depois ou, quando o fazem, é de maneira pontual, sem continuidade. Será que a educação não seria mais dinâmica se tão somente se aproveitasse o essencial do rol de conteúdos para dar mais espaço aos temas transversais como a EA, ou o ambiente fosse o tema gerador dos demais conteúdos ao invés de ser encarado como mais um tópico a ser acrescentado?

Foi questionado se os professores já tinham feito algum curso voltado para a prática da EA (Tabela $5)$.

Tabela 5 - Já fez algum curso voltado para a prática da EA?

\begin{tabular}{|c|c|}
\hline Sim & 5 \\
\hline Não & 9 \\
\hline
\end{tabular}

Fonte: Elaboração do autor, 2016.

Menos da metade relatou que já fez algum curso ligado à educação ambiental. Se a formação inicial não contemplou essa dimensão, como esperar que os mesmos trabalhem em sala de aula essa dimensão de forma segura? Apesar de saber a importância, muitos ficam acomodados ou não encontram tempo para tal, visto que um professor de educação básica hoje, para possuir um salário melhor, precisa trabalhar em mais de uma escola, às vezes nos três turnos e em cidades diferentes. Então, como esperar uma dedicação daquele profissional para o desenvolvimento de um bom trabalho? Diante disso, e para saber o que os professores pensam, foi questionado aos docentes se eles se consideravam preparados para abordar a EA em sala de aula (Tabela 6).

Tabela 6- VocÊ se considera preparado para tratar a EA ma sala de aula?

\begin{tabular}{|c|c|}
\hline Sim & 6 \\
\hline Não & 8 \\
\hline
\end{tabular}

Fonte: Elaboração do autor, 2016.

Como esperado, a maioria respondeu que não se sente preparado. Ou seja, os docentes sabem da importância, mas não se aventuram em abordar a EA, justamente pelo tema não ter sido abordado durante sua formação, ou por não terem procura- do algum curso voltado a essa área.

Outra possível dificuldade é que quando se trabalha a EA na escola, muda-se toda a rotina da mesma. Por ser um conteúdo interdisciplinar, não é trabalhado com notas ou provas além de envolver a preparação de todo um corpo docente. Muitos deles tem dificuldades em trabalhar de forma interdisciplinar por medo de atrasar o conteúdo regular, falta de envolvimento de ouros professores, dificuldade de se trabalhar um tema considerado "diferente" da disciplina ministrada, ausência de recurso financeiro e da escola e planejamento precário ou inexistente. Infelizmente, a falta de preparo dos professores causa o abandono da continuidade dos projetos de EA (BIZERRIL e FARIA, 2001). Nessa perspectiva, foi perguntado se os professores já desenvolveram alguma atividade voltada para a EA em sua disciplina (Tabela 7).

Tabela 7 - VocÊ já desenvolveu alguma atividade voltada para a EA em sua disciplina?

\begin{tabular}{|c|c|}
\hline Sim & 8 \\
\hline Não & 6 \\
\hline
\end{tabular}

Fonte: Elaboração do autor, 2016.

É interessante notar que apesar de a maioria relatar que não se considera preparado para abordar a EA, também a maioria afirma já ter desenvolvido alguma atividade voltada para esse tema, porém, como muitos não se sentem preparados ou não têm formação, não podemos esperar que isto seja feito de forma embasada, crítica e contínua. Infelizmente seis professores, um quantitativo razoável, disseram nunca ter trabalhado o tema em sala de aula.

Para saber então qual a concepção dos professores em relação a esse tema, foi questionado aos docentes o que é EA. A maioria das respostas teve uma base comum, relacionando a EA com orientações que proporcionem melhor relação do homem com seu meio. Geralmente focando na relação homem-natureza, deixando de lado a relação entre as pessoas como parte da EA.

[...] orientação e construção de práticas que primem pelo desenvolvimento de cidadãos que se relacionem com o meio ambiente de maneira sustentável menos 
danosa (Depoimento escrito).

Houve quem colocasse também que educação ambiental:

É aprender a cuidar de forma biologicamente sustentável o ambiente a nossa volta - da nossa casa, da nossa escola, da nossa cidade, do nosso país e do nosso planeta; é formar cidadãos que cuidam dos ambientes a sua volta, sempre com o intuito de deixar um mundo melhor para a próxima geração; é respeitar as leis e documentos que regulamentam a Educação Ambiental. (Depoimento escrito).

A maioria das respostas reportava-se a ações para a preservação ou conservação, focando o papel do homem para com o restante da natureza. Também se colocou que EA

[...] é estimular os alunos a conhecer e praticar ações voltadas ao meio ambiente que visem ao bem de todos em sociedade, destacando a importância e consciência do papel de cada ser de acordo com a harmonia entre animais, habitat e sociedade, visando à sustentabilidade (Depoimento escrito).

[...] são atitudes e conhecimentos voltados para a conservação do meio ambiente (Depoimento escrito).

[...] é construir conhecimentos, valores visando à conservação do meio ambiente (Depoimento escrito).

Para saber se os professores estavam familiarizados com os principais documentos oficiais sobre a EA (Agenda 21, Declaração de Estocolmo, Carta da Terra, Lei Federal n. 9795/99, PCN: Meio ambiente na escola), foi perguntado aos mesmos se conheciam ou já tinham ouvido falar desses documentos. Dos professores abordados, cinco demonstraram não saber ou não recordar de nenhum documento ligado à EA. Um professor informou que, apesar de já ter estudado esses documentos outrora, no momento não recordava, havendo a necessidade de se atualizar. Dois professores relataram como documentos os PCN e a LDB. Um professor informou o Relatório ou estudo de impacto ambiental e a Legislação ambiental. Dois professores informaram que conhecem ou já ouviram falar da Política nacional de educação ambiental e da lei 9.795/99. Um professor relatou a Eco 92 como documento oficial e dois professores relataram os seguintes documentos: Agenda 21, manual do com-vida, Carta da terra, Carta de Belgrado, Manual do PRONEA, Manual escolas sustentáveis, manual vamos cuidar do Brasil, sendo que um demostrou conhecer mais que o outro, visto ter informado menos documentos.

Por fim, foi perguntado aos docentes se os mesmos costumam realizar atividades voltadas à temática ambiental com os alunos e, em caso afirmativo, apontarem qual foi (Tabela 8).

Tabela 8 . Você costuma realizar atividades voltadas à temática ambiental com os alunos?

\begin{tabular}{|c|c|}
\hline Sim & 5 \\
\hline Não & 7 \\
\hline Às vezes & 2 \\
\hline
\end{tabular}

Fonte: Elaboração do autor, 2016.

Dos professores que costumam realizar ou que já realizaram atividades ligadas à temática ambiental, um informou que trabalha com atividades em sala (não especificou exatamente o quê), confecção de cartazes sobre o tema, textos em grupo. Outro professor relatou já ter trabalhado com projeto de coleta seletiva, dengue e plantas em extinção, um professor realizou mostra científica escolar com lixo reciclado, três professores disseram que trabalham esse tema com aulas expositivas, às vezes com atividades lúdicas. Percebe-se então que o desenvolvimento da educação ambiental que faz parte de atividades em sala de aula é na maioria pontual.

Entretanto, um dos professores relatou já ter trabalhado com a criação da "árvore com-vida", explicação sobre os três Rs (reciclar, reutilizar e reduzir), criação de bonecos com materiais recicláveis, debate sobre a importância de manter a sala de aula e a escola limpas. O mesmo informou ter como objetivo ainda para este ano a criação de uma área verde na escola. Ou seja, apenas 
este professor demonstrou contemplar a dimensão ambiental em várias das atividades cotidianas, além de ter um projeto específico planejado.

Portanto, apesar da dificuldade de formação, tempo e conhecimento, nota-se que na EMEF Sérgio Francisco da Silva há um trabalho tímido e pontual de EA com os alunos que precisa ser melhorado e ampliado, começando com o envolvimento de todos na construção e avaliação do PPP escolar. Uma vez que esse documento seja bem reavaliado e atualizado, os professores podem discutir e planejar para abordar a EA durante todo o calendário letivo, seja em suas aulas ou através de projetos com a participação interdisciplinar, o que no momento não ocorre.

Quando um professor trabalha com a EA, geralmente é de forma isolada, sem a participação e cooperação dos outros professores. Além disso, é necessário, através de parcerias com a Secretaria de Educação, promover cursos ligados a esse tema transversal para que os professores possam se capacitar e assim se sentirem mais preparados para abordar a dimensão ambiental.

Mas além da percepção dos professores, foi questionado aos alunos como eles estavam percebendo a EA na escola. Para isso, um questionário foi aplicado, e foi perguntado se os mesmos conhecem o PPP da escola (Figura 1).

Figura 1 - Conhece o Projeto Político Pedagógico da Emef Sérgio Francisco da Silva?

\section{Conhece o PPP da escola?}

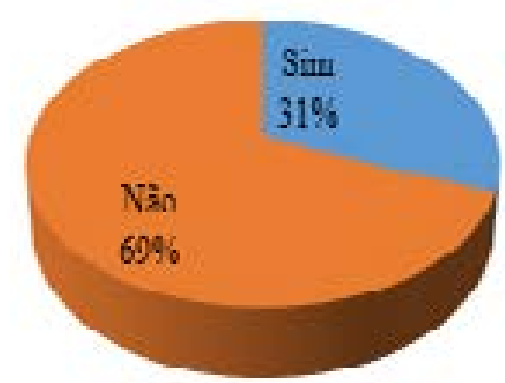

Fonte: Arquivo do autor, 2016.

Dos 45 alunos abordados, apenas $31 \%$ afirmaram conhecer o PPP da escola, o que é até uma marca considerável. É importante o aluno conhecer este documento, pois dessa forma, o próprio tem condições de acompanhar e cobrar dos professores e da coordenação o seu cumprimento e até sugerir mudanças para sua melhoria. Entretanto, a grande maioria afirmou não conhecer o PPP. Isso mostra que na escola não foi feito um trabalho de divulgação com os alunos nem para a comunidade escolar desse documento de maneira oficial.

Ainda no sentido de analisar a comunicação e o trabalho de informações na escola foi questionado aos alunos se os professores criam oportunidades para frequente troca de ideias, inovações e criação conjunta no trabalho em sala de aula (Figura 2).

Figura 2 - Os professores criam oportunidades para frequentes trocas de ideias, inovações e criação conjunta no trabalho em sala de aula?

\section{Os professores criam oportunidades para troca de ideias?}

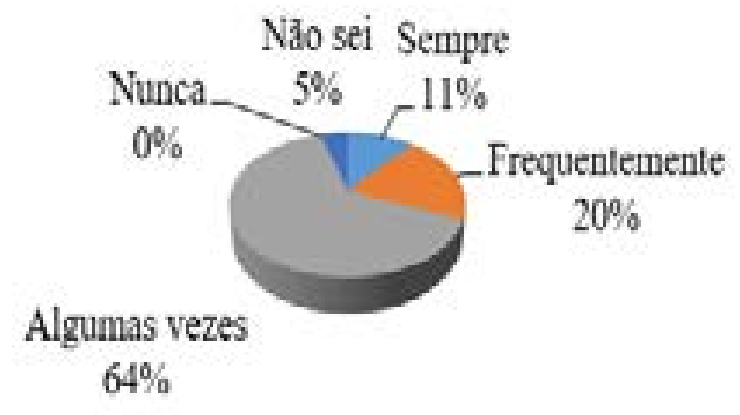

Fonte: Arquivo do autor, 2016.

Somente $11 \%$ dos alunos relataram que os professores sempre criam oportunidades para frequentes trocas de ideias, inovação e criação conjunta em sala de aula. $20 \%$ disseram que os professores frequentemente o fazem. A grande maioria, $64 \%$, afirma que somente algumas vezes é que isso acontece em sala de aula. 5\% não souberam responder.

Se o professor não permite a criação desses momentos, a educação torna-se "bancária", em que o docente, detentor do conhecimento, deposita a informação no aluno, prática essa tão condenada por Paulo Freire. O professor como agente libertador tem a obrigação de problematizar a reali- 
dade do educando, levando-o a se conscientizar de sua realidade e que é possível mudá-la. Isso é educação ambiental que os docentes têm que perseguir e praticá-la com seus alunos (FREIRE, 1987).

E se é um trabalho de parceria, de troca de ideias, é importante também os alunos saberem o que está sendo trabalhado pelo professor. Os docentes precisam problematizar o tema gerador para fazê-los refletir e possibilitar mudança de atitude.

Para sondar o que os alunos sabem acerca do meio ambiente, foi perguntado aos mesmos o que faz parte do meio ambiente. Muitos citaram elementos da fauna e da flora, como árvores, os campos, os mangues, animais, pessoas, flores, jardins e apontaram também elementos da natureza como rios, lagoas, mar, oceanos, chuva, ar, solo, sol.

Outras respostas não elencavam propriamente os elementos e fatores que compõem o meio ambiente, dando respostas genéricas e gerais:

[...] tudo que se une à natureza faz parte do meio ambiente.

[...] faz parte do meio ambiente todo ser que nele vive, sendo um fator importante para a nossa sobrevivência e precisa ser preservado (Depoimento escrito).

Entretanto, nessa pergunta, alguns alunos não entenderam exatamente a proposta e colocaram ações para preservar o meio ambiente, como não jogar lixo no chão, manter os lugares limpos, não derrubar árvores, não poluir o meio ambiente. Um dos alunos indicou além de ações, qualidades do meio ambiente e atitudes que devem ser incentivadas.

[...] cidade limpa, escola limpa, educação, respeito com a natureza [...] você ajudando faz diferença ao meio ambiente (Depoimento escrito).

Outros se referiram ao dia do meio ambiente como sendo o dia da limpeza. O que comprova a ação pontual do trabalho dos professores em relação à comemoração de datas específicas. Um aluno relatou como a consciência faz parte do meio ambiente. Três alunos não entenderam a pergunta e colocaram respostas distantes do objetivo da mesma.
Foi perguntado como o discente fica sabendo de informações sobre o meio ambiente (Figura 3).

Figura 3 - Como você fica sabendo de informações sobre o meio ambiente?

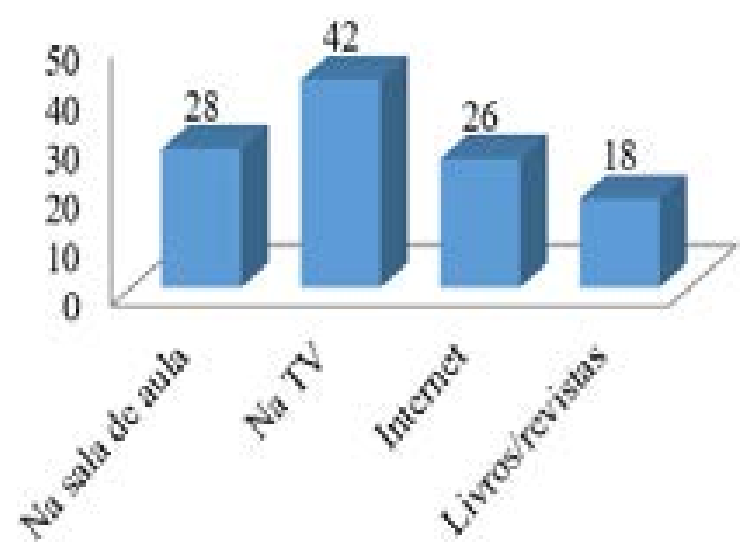

Fonte: Arquivo do autor, 2016.

Pelo gráfico acima se pode constatar que a TV ainda é o meio de comunicação mais influente na comunidade, até mesmo mais que a internet que ficou em terceiro lugar. Felizmente pouco mais da metade dos alunos que responderam ao questionário indicaram que a sala de aula é um dos locais onde eles se informam sobre o meio ambiente. Por último, ficaram os livros e revistas como meio informativo a respeito desse tema. Isso demostra que apesar da abordagem branda da educação ambiental, o professor ainda é um dos principais responsáveis por sensibilizar a nova geração reforçando a importância do seu trabalho. Não basta saber onde o alunado obtém informações acerca do meio ambiente, mas qual a importância que há nesse fato. Por isso foi questionado se se falar sobre o meio ambiente seria importante para o aluno (Figura 4). 
Figura 4 - Falar sobre o meio ambiente é importante para você?

\section{Falar sobre o meio ambiente é importante?}

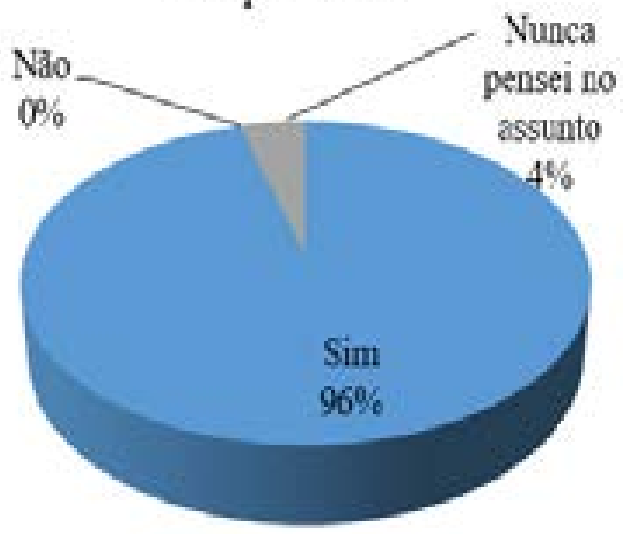

Fonte: Arquivo do autor, 2016.

Cerca de $96 \%$ do total de alunos responderam que sim; é importante para o aluno. Somente 4\% afirmaram que nunca tinham pensado no assunto. Isso demostra que eles estão abertos ao aprendizado e ao debate desse tema transversal, por compreenderem a importância. Cabe então ao professor sondar quais problemas ambientais assolam a comunidade e trabalhar em cima deles. A partir da realidade, o aluno absorve melhor o que deve ser aprendido e tem condições de mudá-la para melhor. Por isso foi perguntado também aos alunos quais problemas ambientais eles encontram em sua casa, rua, escola ou em seu bairro (Figura $5)$.

Figura 5 - Quais problemas ambientais você encontra em sua casa, rua, escola ou em seu bairro?

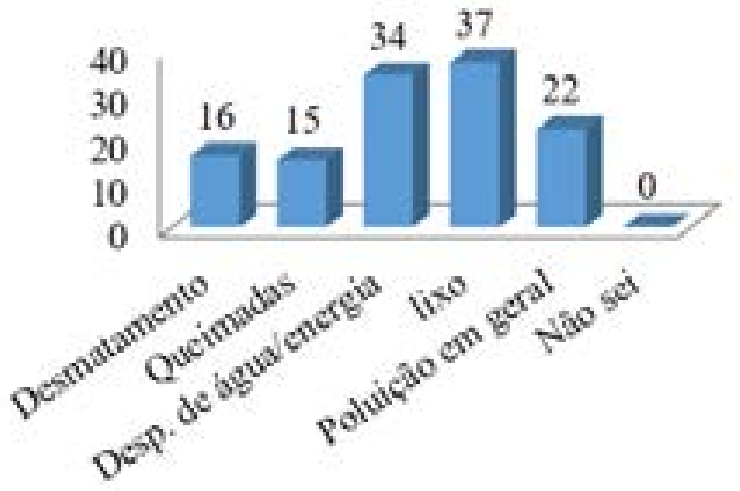

Fonte: Arquivo do autor, 2016.

Das alternativas apresentadas, os dois problemas ambientais que se destacaram foram a problemática do lixo e o desperdício de água e/ou energia.
Problemas esses diagnosticados na escola e/ou no ambiente familiar comunitário. A partir da identificação do problema, o professor pode elaborar projetos interdisciplinares ou ações em EA com o objetivo de sanar ou minimizar esses problemas. Infelizmente muitos professores não procuram saber a realidade do aluno, passando informações vagas ou já prontas de outras realidades distantes da do discente. Este muitas vezes não consegue assimilar a importância, e o pior, não pode colocar em prática o que aprende na escola para mudar sua realidade, que é o objetivo da educação. Sendo a EA interdisciplinar, todas as disciplinas precisam trabalhá-la. Foi perguntado então aos alunos em quais disciplinas eles são informados sobre o meio ambiente (Figura 6).

Figura 6 - Em quais disciplinas você é informado sobre o meio ambiente?

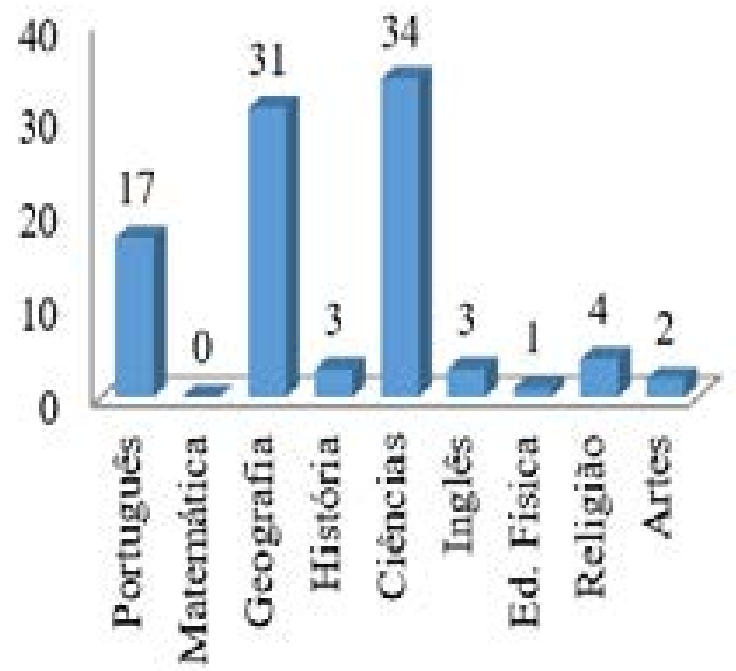

Fonte: Arquivo do autor, 2016.

Foi constatado que as disciplinas que mais abordam esse tema em suas aulas são Ciências, seguida de Geografia e Português. O restante das disciplinas apresentou baixo índice de apontamento. Esse resultado já era esperado, visto que quando se tem alguma atividade envolvendo a EA, as disciplinas Ciências e Geografia são as que mais se envolvem. Mas isso não tira a responsabilidade das demais. De acordo com o gráfico, fica claro que nem todos os professores abordam a temática ambiental em suas aulas, em seus planejamentos.

Se a EA não for trabalhada de forma interdisciplinar, os resultados não terão a potencialidade que podem alcançar. Toda e qualquer iniciativa 
nesse sentido encontrará mais entraves para se concretizar.

Foi questionado também se os alunos já tinham participado de alguma atividade envolvendo a EA (Figura 7).

Figura 7 - Você já participou de alguma atividade envolvendo a educação ambiental?

\section{Você já participou de alguma atividade envolvendo educação ambiental?}

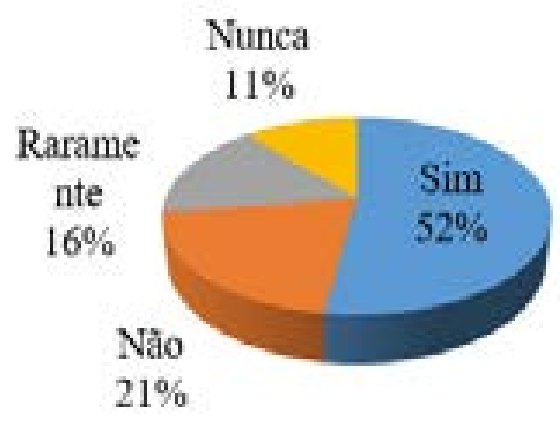

Fonte: Arquivo do autor, 2016.

Mais da metade, $52 \%$ informaram que sim, já tinham participado de alguma atividade envolvendo a EA. 16\% disseram que raramente participam. $21 \%$ e $11 \%$ relataram que não e nunca participaram, respectivamente. Dos alunos que participaram, provavelmente o fizeram nas aulas de Ciências, Geografia ou Português, como relataram antes. Mas muito provavelmente em ações pontuais e não contínuas, como exposto pelos professores. Por causa disso, foi questionado aos alunos se os professores abordam a EA com alguma frequência nas aulas (Figura 8).
Figura 8 - Os professores abordam a educação ambiental com alguma frequência nas aulas?

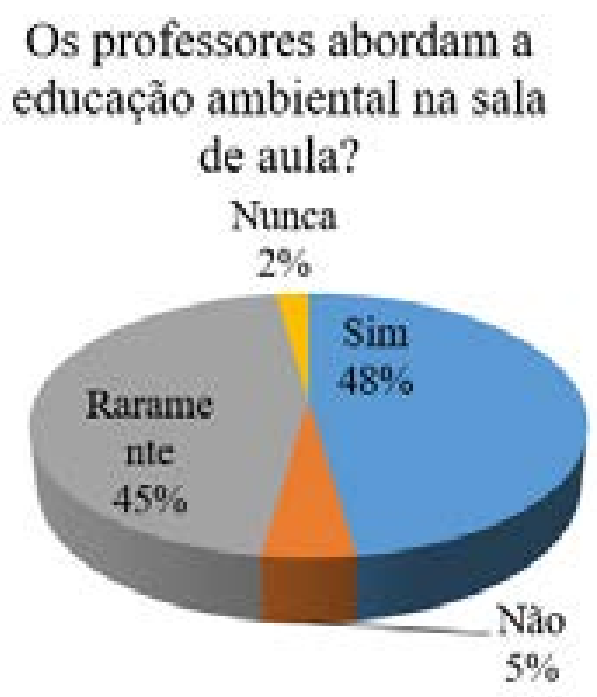

Fonte: Arquivo do autor, 2016.

Provavelmente, as matérias em que os alunos ouvem falar sobre EA na escola, são as de responsabilidade dos docentes que abordam esse tema. $48 \%$ dos alunos abordados na pesquisa informaram que sim, os professores abordam esse tema. $45 \%$ disseram que raramente abordam. $5 \%$ e $2 \%$ relataram que não e nunca abordam, respectivamente. Esse percentual de professores que aborda a EA ainda é muito baixo para se atingir pelo menos um patamar razoável.

Mas apesar de nem todos os professores abordarem o tema, se quis saber dos alunos o que seria EA para eles. Alguns relataram algo próximo a que é se educar para não jogar lixo nas ruas, cuidar da natureza, do espaço que a pessoa vive, não desmatar, manter os lugares limpos; é

[...] não fazer nada de mal para o ambiente em que tiramos a maioria da nossa alimentação (Depoimento escrito).

Outros relataram algo parecido com:

[...] aprender o que é conservar o mundo para no futuro não precisar obter medidas drásticas (Depoimento escrito).

Também relataram que educação ambiental seria:

[...] manter o lugar onde vivemos em perfeita condição de vida (Depoimento escrito).

[...] educação ambiental é cuidar mais da natureza, aumentando assim nossa esti- 
mativa de vida (Depoimento escrito).

[...] é a educação que nos ensina como cuidar do nosso planeta, do meio ambiente (Depoimento escrito).

Os alunos também informaram que a EA é tudo que fala sobre a fauna e a flora e:

[...] é uma maneira de saber um pouco sobre o meio ambiente (Depoimento escrito).

Também foram constatadas respostas aleatórias distantes do objetivo da questão.

As respostas dos alunos estão alinhadas com as de seus professores no sentido da necessidade de preservação e conservação do ambiente. As dos alunos ainda mais ligadas ao meio natural como fauna e flora, deslocando o homem do restante da natureza.

\section{Considerações finais}

Nota-se que na EMEF Sérgio Francisco da Silva há atividades relacionadas a EA, entretanto, é um trabalho pontual, não interdisciplinar e por meio de atividades de poucos professores, de disciplinas específicas como Ciências e Geografia começando pelo seu PPP, que não aborda com clareza esta dimensão.

Os alunos possuem uma noção vaga e parcial da EA, resumindo-se em atitudes de preservação do meio ambiente natural e mostrando a necessidade de se trabalhar a dimensão ambiental de forma crítica na escola.

Para isso, vemos a necessidade da constante atualização dos professores, principalmente para aqueles que não foram contemplados com a EA em sua formação. Isso mostra a importância da formação continuada para fomentar o desenvolvimento da Educação Ambiental na escola.

Outra medida para melhorar o trabalho da escola com o tema é a atualização constante do PPP da unidade de ensino, com participação efetiva dos docentes e discentes na sua elaboração, bem como sua apresentação e discussão por toda a comunidade escolar para divulgação e conhecimento.
Refletir sobre o meio ambiente visando à adoção de atitudes mais responsáveis, locais e globais é importante, a fim de que a escola tenha um compromisso sério, de formar cidadãos conscientes, críticos e sustentáveis que se preocupem com o meio ambiente e interfiram nele positivamente.

\section{Referências bibliográficas}

BIZERRIL, M. X. A.; FARIA, D. S. Percepção de professores sobre a Educação Ambiental no Ensino Ambiental. Revista Brasileira Estudos Pedagógicos, v. 82, n. 202, p. 57 - 69, 2001.

BRASIL. Presidência da República. Lei n. 9795, de 27 de abril de 1999. Dispõe sobre a educação ambiental, institui a Política Nacional de Educação Ambiental e dá outras providências. Coleção de leis da República Federativa do Brasil. Brasília (DF): Casa Civil, 1999 Disponível em: <http://www.planalto.gov.br/ccivil03/Leis/ L9795.htm>. Acesso em: fevereiro de 2016.

BRASIL. Conselho Nacional de Educação. Resolução n. 2, de 15 de junho de 2012. Estabelece as Diretrizes Curriculares Nacionais para a Educação Ambiental. Diário oficial da União, Brasília (DF), 2012. Disponível em: <http://conferenciainfanto.mec.gov.br/images/ pdf/diretrizes. pdf $>$. Acesso em: 28 de julho de 2016.

BRASIL. Instituto Nacional de Estudos e Pesquisas Educacionais Anísio Teixeira (INEP). Resultados e metas do IDEB, 2015. Disponível em: http://ideb.inep.gov.br/resultado/resultado/resultado.seam?cid=1503839. Acessado em: 28 de julho de 2016.

CARMO, R. L. População e mudanças ambientais globais. Revista Multiciência. Campinas, $n$. 8, p. 65-87, 2007.

CUBA, M. A. Educação ambiental nas escolas. Revista Educação, Cultura e Comunicação ECСОМ. [S.1.], v. 1, n. 2, p. 23-31, 2010.

EFFTING, T. R. Educação Ambiental nas escolas públicas: realidade e desafios. 2007. 90 f. TCC (Especialização em Planejamento para o desenvolvimento sustentável) -Centro de Ciências Agrárias, Universidade Estadual do Oeste do 
Paraná, Marechal Cândido Rondon, 2007.

ESTEVAM, F. H. C.; PESTANA, G. S.; LEAL, T. R. Ambientalismo: uma perspectiva histórica. 23 f. Trabalho para obtenção de créditos (História das sociedades contemporâneas) -Universidades Federal de Pernambuco, Recife, 2008. Disponível em: $<$ http://pt.slideshare.net/pedro_s/histria-do-ambientalismo>. Acesso em: julho de 2016.

FELIZOLA, M. P. M.; COSTA, F. P. O ambientalismo em Sergipe - um percurso histórico dos movimentos ambientais entre 1983-2011. Revista Brasileira de História e Ciências Sociais. São Leopoldo, v. 4, n. 8, p. 317-337, 2012.

FREIRE, P. Pedagogia do oprimido. 11. ed. Rio de Janeiro: Paz e Terra, 1987.

GADOTTI, M. Pedagogia da terra. 6. ed. São Paulo: Peirópolis, 2006.

GALLO, S. Transversalidade e meio ambiente. In: CICLO DE PALESTRAS SOBRE MEIO AMBIENTE, 1., 2001. Brasília. Anais ... Brasília: MEC/SEF, 2001. p. 15-26

JACOBI, P. Educação Ambiental, cidadania e sustentabilidade. Cadernos de Pesquisa, São Paulo, v. 118, n. 1, p. 189-205, 2003.

LECLERC, G. F. E.; MOLL, J. Programa Mais Educação: avanços e desafios para uma estratégia indutora da educação integral e em tempo integral. Educar em Revista, n. 45, p. 91 - 110, 2012.

LONGHI, S. R. P.; BENTO, K. L. Projeto Político Pedagógico: uma Construção Coletiva. Revista de divulgação técnico-científica do ICPG, [S.1.], v. 3, n. 9, p. 173-178, 2006.

PELEGRINI, D. F.; VLACH, V. R. B. As múltiplas dimensões da Educação ambiental: por uma ampliação na abordagem. Sociedade e Natureza, v. 23, n. 2, p. $187-196,2011$.
Sobre os autores

Ann Letícia Aragão Guarany: Mestra em Educação pela - UFS, e-mail: annleticia@hotmail. com.

Davi Prado Lima: Mestre em Biotecnologia pela - UFS, e-mail: jdplima5@gmail.com. 